\title{
Factors Influencing Pre-service Teachers' Satisfaction and Intention to Use the Internet: A Structural Equation Modeling
}

\author{
https://doi.org/10.3991/ijim.v15i02.13503 \\ Ali Sadikin, Akhmad Habibi ${ }^{(凶)}$, Erick Sanjaya \\ Universitas Jambi, Jambi, Indonesia \\ akhmad.habibi@unja.ac.id \\ Dwi Candra Setiawan \\ IKIP Budi Utomo, Malang, Indonesia \\ Try Susanti \\ UIN Sulthan Thaha Saifuddin, Jambi, Indonesia \\ Ferdiaz Saudagar \\ Universitas Jambi, Jambi, Indonesia
}

\begin{abstract}
The current study aimed at exploring factors influencing Indonesian pre-service teachers' satisfaction and intention to use the Internet for learning. Implementing an extended technology acceptance model, data were gathered from 596 Indonesian pre-service teachers from five universities. The measurement and the assessment of the model were computed through partial least square structural equation modeling. For the measurement model, we computed data's reflective indicator loadings, internal consistency reliability, convergent validity, and discriminant validity. Meanwhile, the reports of the constructs' relationships, coefficient determination (R2), effect size of f,2 and predictive relevance $(\mathrm{Q} 2)$ were addressed for the assessment of the structural model. The model was valid and reliable that informed six significant relationships out of eight hypotheses. The pre-service teachers' satisfaction using the Internet for learning was strongly influenced by perceived ease of use and intention to use. Meanwhile, their intention to use the Internet was strongly influenced by their attitude, perceived usefulness, and perceived ease of use. Recommendation and suggestion were offered for the betterment of Indonesian education.
\end{abstract}

Keywords - Internet, higher education, intention to use, structural equation modeling

\section{$1 \quad$ Introduction}

The world has changed rapidly where the use of the Internet has expanded in all areas of life, such as education, economy, health, business, and industry. Governments 
in developing countries are now in the race of bringing the digital era as their top priorities to manage the change. Most of these countries encourage internet access by connecting the services to all people in their country [1]. Regarding the development of technology, internet access has been widely provided and available as a very important source for education. The Internet, especially wireless technology, has emerged in some forms of learning such as e-learning and m-learning [2]. Some studies have developed to inform the capability of the Internet application in education to encourage knowledge acquisition [3]. In addition, recent studies have also reported the positive impacts of the Internet in promoting pre-service teachers' interaction, flexibility in learning, physical mobility, self-monitoring, and metacognition improvement.

In spite of the ubiquitous studies regarding the application of the Internet in higher educational level, there are limited studies about contributing factors influencing the satisfaction and intention to use the Internet for learning among pre-service teachers [4]. To achieve the purposes of the study, an extended Technology Acceptance Model (TAM) was implemented; besides the three main factors of the TAM (Perceived Ease of Use or PEU, Perceived Usefulness or PU, and Attitude or AT), Satisfaction (ST) was added as the extended factor. ST is an essential indicator for both e-learning and $\mathrm{m}$-learning. It is reported to have a connection with the improvement of pre-service teachers' academic persistence and success [3].

\section{Literature Review}

The adoption of the Internet in higher education is very crucial to achieve transformation in teaching and learning activities [1]. The Internet can function as a transforming tool for all educational stakeholders, especially students to actively use technology in learning [3]. It can improve the learning environment and encourage innovation in learning. In general, the Internet supports the establishment of the concept of group-based learning, practical flexibility, content and learning creativity, and personal learning.

\subsection{Technology Acceptance Model (TAM) and Satisfaction (ST)}

In this study, TAM was adapted as a guideline framework accompanied by Satisfaction (ST). The TAM was founded by Davis in 1989 [5] extending the theory of reasoned action. In this study, it consists of three main constructs; 1) PEU, PU, and AT to predict Intention to Use (IU). Many studies have extended TAM [5] by adding additional factors facilitating its functions [e.g., 6, 7, 8, 9]. However, few studies have been done by extending ST into the original TAM [4]. ST is the extent factor whether the adoption of technology is in line with the needs, experiences, and emerging values when users use the technology [4]. We applied ST as an extended factor of TAM in order to understand its influences on Indonesian pre-service teachers' IU (Figure 1). 


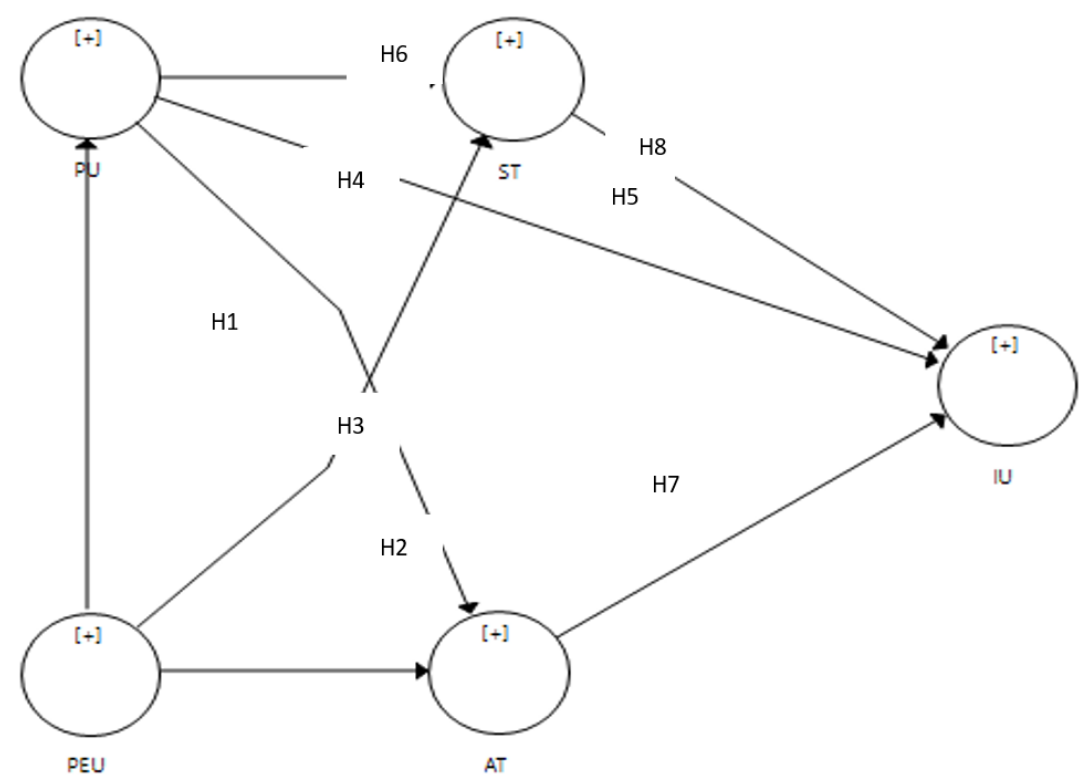

Fig. 1. Proposed model

\subsection{Perceived Ease of Use (PEU)}

PEU in this study is defined as pre-service teachers' perception of the way of easiness to use the Internet service for their learning. PEU has been informed to significantly influence PU and AT in many studies involving the Internet and its components $(8,9,10)$. YouTubers' PEU had statistically correlation with PU and AT [10]. Meanwhile, [8] reported that PEU has significantly predicted PU and AT in mlearning activities. Also, PEU positively influenced PU and IU regarding Google group applications on the Internet [9]. In affecting ST, PEU is also informed to have a strong correlation in mobile technology [10]. These works of literature guide to three hypotheses for this study;

H1. PEU would have a positive influence on PU.

H2. PEU would have a positive influence on AT

H3. PEU would have a positive influence on ST

\subsection{Perceived Usefulness (PU)}

In this study, PU is informed as pre-service teachers' perceptions about the beneficial factors obtained from using the Internet service provided by the higher education institutions. PU is one of the significant constructs to influence AT, IU, and ST. In some studies, PU was reported to predict AT and IU [e.g., 4, 6, 9]. For example, [9] informed that PU had a big influence in predicting IU to foster student achievement and promoting knowledge sharing. Similarly, in predicting AT, PU was 
also among the effective predictors in the adoption of ICT during learning activities [6]. Regarding ST, PU has also been involved in some studies [e.g., 4, 11] that reported strong relationships. However, a low path effect between PU and ST ( $\beta=$ .190) was also informed [2].

H4. PU would have a positive influence on AT

H5. PU would have a positive influence on IU

H6. PU would have a positive influence on ST

\subsection{Attitudes (AT)}

The current study refers AT as pre-service teachers' certain behavior connected with the use of the Internet. AT has been a key predictor in influencing IU $[6,12]$. Hence, AT was also involved in his study.

H7. AT would have a positive influence on IU.

\subsection{Satisfaction (ST)}

$\mathrm{ST}$ in this study is defined as the extent to which the adoption of technology related to the need, experiences, and emerging values when pre-service teachers use the Internet [4]. The construct has been widely reported to have predicted IU in many studies [e.g., 13, 14]

H8. ST would have a positive influence on IU.

\section{$3 \quad$ Method}

The researchers applied a survey as one of the non-experimental designs in a quantitative culture which has been conducted in numerous fields of study. The entire population is all Indonesian pre-service teachers, more than 1 million. In addition, the target population of this study is Indonesian pre-service teachers who have been provided by the service of the Internet in their higher education learning. The study was funded by Universitas Jambi through its research center, No: 9175/UN/2019. The researchers established the instrument by adapting items from previous related studies and proceeded 596 responses for the main data analysis through Statistical Package for Social Studies (SPSS) and Partial Least Square Structural Equation Modeling (PLS-SEM); SPSS 23.0 and SmartPLS 3.0 were tools for the data analysis.

\subsection{Establishing the instrument}

The threats of the validity in this survey study are bias of publication selection, data extraction inaccuracy, and misclassification [15]. Through a careful selection and adaptation of the items from previous related journals, the instrument of the current study was established. In addition, face and content validity procedures were conducted. To reduce the issue of data extraction inaccuracy, pilot study was conducted to examine the reliability of the data. For the misclassification, 
measurement model was chosen to extract factors affecting intention to use the Internet for learning. This study adapted the questionnaire from previous studies $[4,5$, 7, 8] and a 5-point Likert scale from 'strongly disagree' to 'strongly agree' was implemented. There were 22 indicators included in this adaptation stage. Before collecting the main data to empirically measure and assess the model, the questionnaire was validated through the face and content validity as well as a pilot test. Five pre-service teachers as users (face) and five Ph.D. researchers as experts (content) checked the items of the instrument. Using two sessions of focus group discussion, the users and experts were requested to discuss and address their concern regarding the items to fit the context and settings of the study. Based on the feedback obtained from the discussions, the sentences' dictions and structures of some indicators were modified for the betterment of the understanding of the participants; the order of some indicators was revised for facilitating an appropriate sequence. Finally, two indicators were dropped based on the feedback of the experts because the context is not in line with the Indonesian higher education contexts. The items were translated using back translation [16] involving two linguistics experts. To further purify the instrument, it was piloted to 57 pre-service teachers in order to report the instrument's reliability through the examination of Cronbach's alpha for each construct; the values ranged from .800 and .940 . The results indicated that the constructs involved had no issues with the reliability. Twenty indicators were established after all processes, from adaptation to the assessment of pilot study data.

\subsection{Data collection}

The procedures for the main data collection were begun after the examination of the first reliability from the piloting procedure. The inclusion criterion applied in this study's samples was pre-service teachers with personal computers, laptops, or smartphones with the Internet connection. The data collection time was from January to July 2019. Six hundred and fifteen pre-service teachers from four universities filled in the questionnaires. After removing 19 data due to incomplete responses, 596 responses were further analyzed. The participants consisted of 95 (15.93\%) males and 501 females $(84.06 \%)$ whose ages between 19 and 22 years old. The sample of this study was deemed sufficient in implementing PLS-SEM [17]. Data were analyzed using SPSS version 23.0 and SmartPls 3.0.

\subsection{Data analysis}

Prior to the main data analysis, the raw data were assessed for missing data, outliers, and normality [18]. Missing data with higher percentage (>5\%) were eliminated while responses with less than $5 \%$ of missing data were fixed by replacing the responses' missing value with the median value (3). Using the SPSS, outliers were recognized by a box plot for each construct. For the univariate normality of the construct, the values were that the skewness and kurtosis for each indicator should range between-1.96 and +1.96 at $5 \%$ of significance level. No correlation valued at 
.900 showing that the multicollinearity was not an issue for the data. The data were then computed for the assessment of measurement and structural model.

Two stages of data analysis were conducted; measuring the model for establishing the data construct validity and assessing the model to determine the relationship between constructs. In measuring the model, four measurements were applied namely reflective indicator loadings with a threshold value of .700 [19, 20, 21], internal consistency reliability using Cronbach's alpha and Composite Reliability (between > .800 and <.950), convergent validity with Average Variance Extracted of $>.500$, and discriminant validity using Fornel-Larcker Criterion, cross-loading and HeterotraitMonotrait. On the other hand, five assessments were used in assessing the model; the reports of Variance Inflation Factor (VIF) values, path coefficient, coefficient determination (R2), effect size of f,2 and predictive relevance (Q2). The explanation of each stage and the threshold for the structural model assessment can be seen in Table 1 .

Table 1. Stages of assessing the model [16]

\begin{tabular}{|l|l|}
\hline \multicolumn{1}{|c|}{ Structural model } & \multicolumn{1}{c|}{ Threshold } \\
\hline Collinearity $(\mathrm{VIF})$ & $\mathrm{VIF}<3.000$ \\
\hline Path coefficients $(\beta)$ & $\mathrm{p}<.005$ \\
\hline Coefficient determination $\left(R^{2}\right)$ & .750 (substantial), .500 (moderate), and .250 (weak). \\
\hline Effect size of $f^{2}$ & .020 (small), .150 (medium), and .350 (large) \\
\hline predictive relevance $\left(Q^{2}\right)$ & .020 (small), .150 (medium), and .350 (large) \\
\hline
\end{tabular}

\section{$4 \quad$ Findings}

\subsection{Assessing reflective measurement the model}

We utilized PLS-SEM algorithm in SmartPLS 3.0 to measure the reflective indicator loadings [17]. The indicator loadings recommended for this study were $>.708$ [17]. Two indicators, IU 4 and PU5 were dropped due to the detection of low reflective loadings. After the dropping procedure, most items exceeded the indicator loadings; IU2 achieved the highest loading of .936 while the lowest loading of 773 was earned by ST1.

After the dropping process in the first step of measurement model assessment, the researchers computed the internal consistency reliability, an evaluative procedure to understand the results across items consistency [17]. In PLS-SEM method, Cronbach's alpha and composite reliability should be computed [17, 19]. The values for the reliability should be between 0 and 1; the more a construct has the score, the higher level of reliability is informed. The values of Cronbach's alpha and composite reliability should exceed .800 and be lower than .950 that can be defined as indicator redundancies [17]. Table 2 performs the values of the Cronbach's alpha and composite reliability; all values have met the cut-off points used in this study $(>.800$ and $<.950)$. 
Table 2. Measuring the model: loadings, $\alpha, \mathrm{CR}$, and AVE

\begin{tabular}{|l|c|c|c|c|c|}
\hline Construct & Item & loading & $\boldsymbol{\alpha}$ & CR & AVE \\
\hline Attitude (AT) & AT1 & .849 & .817 & .890 & .730 \\
\hline & AT2 & .855 & & & \\
\hline & AT3 & .860 & & & \\
\hline Intention to Use (IU) & IU1 & .929 & .914 & .945 & .852 \\
\hline & IU2 & .936 & & & \\
\hline & IU3 & .904 & & & \\
\hline Perceived Ease of Use (PEU) & PEU1 & .862 & .908 & .936 & .784 \\
\hline & PEU2 & .872 & & & \\
\hline & PEU3 & .909 & & & \\
\hline & PEU4 & .898 & & & \\
\hline Perceived Usefulness & PU1 & .824 & .835 & .890 & .669 \\
\hline & PU2 & .857 & & & \\
\hline & PU3 & .778 & & & \\
\hline & PU4 & .810 & & & \\
\hline Satisfaction (ST) & ST1 & .773 & .831 & .885 & .659 \\
\hline & ST2 & .813 & & & \\
\hline & ST3 & .853 & & & \\
\hline & ST4 & .805 & & & \\
\hline
\end{tabular}

For the convergent validity, AVE is suggested to elaborate as the metric to measure [17]. In calculating the AVE, we applied SmartPLS algorithm. The recommended AVE value should be $>.500$ that explains $50 \%$ or more of the variance of the construct items. The values of AVE also exceed .500 informing the establishment of convergent validity or $50 \%$ of the variance (Table 2 ).

Meanwhile, for the discriminant validity (Tables 3, 4, and 5), the values of FornellLarcker criterion are shown by square values of AVEs showing AVEs on one construct are greater than all of its loadings with other constructs [17]. Table 4 performs that the indicator's loading value (italic) on its construct is greater than that of all of its cross-loadings in other constructs. The critical value for HeterotraitMonotrait ratio should be below $.850[17,19]$. Shown in Table 5, all values are below the threshold. Through the results of bootstrapping (resampling of 5000) for the Heterotrait-Monotrait value, the confidence intervals show that the values are below 1 indicating that all HTMT values are significantly different from 1. Based on the result of the three assessments, the discriminant validity of the model has been established.

Table 3. Discriminant validity: Fornell-Larcker criterion

\begin{tabular}{|l|c|c|c|c|c|}
\hline & AT & IU & PEU & PU & ST \\
\hline AT & & & & & \\
\hline IU & .805 & & & & \\
\hline PEU & .736 & .636 & & & \\
\hline PU & .726 & .634 & .804 & & \\
\hline ST & .470 & .356 & .440 & .325 & \\
\hline
\end{tabular}


Table 4. Discriminant validity: Cross-loading analysis

\begin{tabular}{|l|l|l|l|l|l|}
\hline & AT & IU & PEU & PU & ST \\
\hline AT1 & .849 & .711 & .590 & .526 & .328 \\
\hline AT2 & .855 & .512 & .519 & .496 & .387 \\
\hline AT3 & .860 & .568 & .517 & .517 & .339 \\
\hline IU1 & .708 & .929 & .547 & .566 & .305 \\
\hline IU2 & .626 & .936 & .526 & .509 & .296 \\
\hline IU3 & .619 & .904 & .530 & .461 & .304 \\
\hline PEU1 & .550 & .475 & .862 & .611 & .360 \\
\hline PEU2 & .553 & .528 & .872 & .567 & .314 \\
\hline PEU3 & .570 & .531 & .909 & .629 & .373 \\
\hline PEU4 & .586 & .518 & .898 & .672 & .350 \\
\hline PU1 & .506 & .490 & .572 & .824 & .262 \\
\hline PU2 & .533 & .466 & .575 & .857 & .253 \\
\hline PU3 & .477 & .415 & .538 & .778 & .185 \\
\hline PU4 & .452 & .449 & .610 & .810 & .241 \\
\hline ST1 & .259 & .221 & .283 & .175 & .773 \\
\hline ST2 & .188 & .166 & .246 & .137 & .813 \\
\hline ST3 & .437 & .346 & .358 & .309 & .853 \\
\hline ST4 & .371 & .278 & .362 & .264 & .805 \\
\hline
\end{tabular}

Table 5. Discriminant validity: HTMT

\begin{tabular}{|l|l|l|l|l|l|}
\hline & AT & IU & PEU & PU & ST \\
\hline AT & .855 & & & & \\
\hline IU & .708 & .923 & & & \\
\hline PEU & .638 & .579 & .885 & & \\
\hline PU & .602 & .557 & .702 & .818 & \\
\hline ST & .409 & .327 & .395 & .289 & .811 \\
\hline
\end{tabular}

\subsection{Assessing the model}

Before computing the data for the structural model assessment, the sets of predictors were assessed for Collinearity by reporting the VIF. For this study model, the VIF was examined for AT, PU, PEU, and IU as the predictors. All VIF values shown in Table 6 are lower than 3.000 which is the threshold implemented for this study [16]. It indicates that the Collinearity is not a problem for the model.

In examining the relationships between exogenous and endogenous variables, the researchers computed the data through a bootstrapping process. Using 5,000 subsamples as suggested by previous studies [17, 19], a 5\% significance relationship was reported to support the hypotheses. All relationships but PU to ST and ST to IU are reported to be significant (Table 2). In detail, hypothesis 1 is supported; PEU is reported to have a significant predicting power to $\mathrm{PU}(\beta=.702 ; \mathrm{t}=27.328 ; \mathrm{p}<0.01)$. PEU also significantly predicts AT $(\beta=.426 ; \mathrm{t}=8.656 ; \mathrm{p}<0.01)$ that supports the statement of hypothesis 2. In predicting ST (H3), PEU is also reported to be significant $(\beta=.379 ; \mathrm{t}=7.081 ; \mathrm{p}<0.01)$. For hypothesis 4 and 5 , PU significantly affected AT $(\beta=.303 ; \mathrm{t}=5.941 ; \mathrm{p}<0.01)$ and IU $(\beta=.203 ; \mathrm{t}=4.966 ; \mathrm{p}<0.01)$ 
while it does not significantly predict ST $(\beta=.023 ; \mathrm{t}=.406 ; \mathrm{p}=.674)$; therefore, hypothesis 7 is not supported. Similarly, hypothesis 8 was also not supported; ST is not a significant predictor for IU $(\beta=.034 ; \mathrm{t}=1.043 ; \mathrm{p}=.299)$. However, AT is reported to be significant in predicting IU $(\beta=.572 ; \mathrm{t}=14.912 ; \mathrm{p}<0.01)$ supporting hypothesis 8 .

Table 6. Collinearity (VIF)

\begin{tabular}{|l|c|c|c|c|c|}
\hline & AT & IU & PEU & PU & ST \\
\hline AT & & 1.732 & & & \\
\hline IU & & & & & \\
\hline PEU & 1.969 & & & 1.000 & 1.969 \\
\hline PU & 1.969 & 1.573 & & & 1.969 \\
\hline ST & & 1.205 & & & \\
\hline
\end{tabular}

Table 7. The relationship among components

\begin{tabular}{|l|l|c|c|c|}
\hline \multicolumn{1}{|c|}{ H } & \multicolumn{1}{|c|}{ Relationship } & $\boldsymbol{\beta}$ & $\boldsymbol{p}$ & Significance \\
\hline H1 & PEU -> PU & .702 & $\mathrm{p}<.01$ & \\
\hline H2 & PEU -> AT & .426 & $\mathrm{p}<.01$ & \\
\hline H3 & PEU - > ST & .379 & $\mathrm{p}<.01$ & \\
\hline H4 & PU -> AT & .303 & $\mathrm{p}<.01$ & \\
\hline H5 & PU -> IU & .203 & $\mathrm{p}<.01$ & \\
\hline H6 & PU -> ST & .023 & .674 & No \\
\hline H7 & AT -> IU & .572 & $\mathrm{p}<.01$ & No \\
\hline H8 & ST -> IU & .034 & .299 & \\
\hline
\end{tabular}

To support the examination of the path coefficient, $t$ value, and $p$ value of the data, the result of the coefficient determination (R2), effect size of $\mathrm{f} 2$, and predictive relevance (Q2) were also informed. Based on the result, the R2 value for AT is .452 (weak), for IU (.527, moderate), and PU (.492, weak), which means that the data have a good level of predicting accuracy; however, ST has no predicting accuracy (.154). For the effect size of f2, the value of PEU to PU (.969) is the largest followed by AT to IU with 401 (large) and PEU to AT (.168, large). On the other hand, the effect sizes of $\mathrm{f} 2$ between PU and AT (.086), PU and IU (.056), and PEU and ST (.087) are categorized as "small". No effect sizes of f2 between IU and ST (.001) as well as PU and ST (.000). Last measurement, cross-validated redundancy measure (Q2) to measure predictive relevance which was done through the blindfolding process in PLS-SEM resulting IU to have the largest Q2 value (.423) followed by AT with the value of .310 (medium) and PU with .310 (medium). ST has the smallest predictive relevance value of .099 (small). From these results, it is proven that the Q2 values of all constructs support the model's predictive relevance for all five endogenous constructs. 


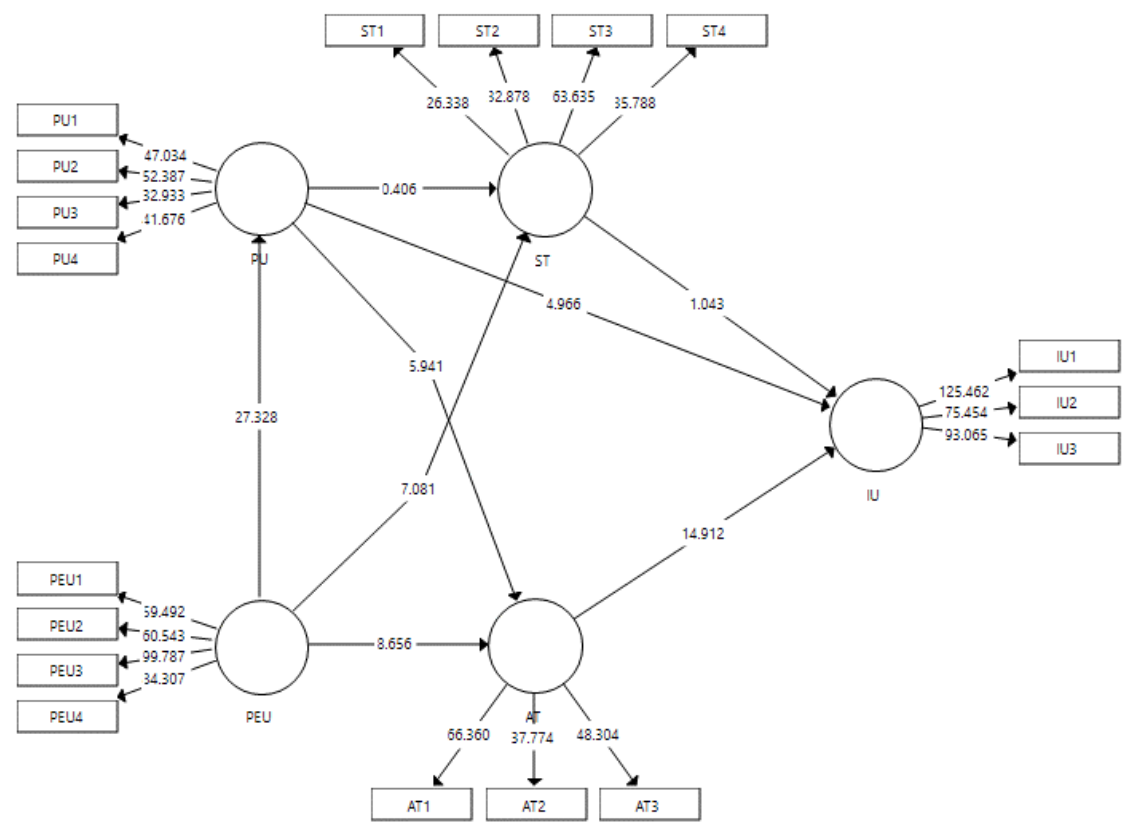

Fig. 2. Final model; $t$ value

\section{Discussion}

One of the purposes of the current research was to measure and assess a model of factors influencing Indonesian pre-service teachers' satisfaction (ST) and intention to use (IU) the Internet for learning through an extended Technology Acceptance Model (TAM) that has also been discussed in numerous previous studies [e.g., 4, 10, 22, 23]. This current study's path analysis informs that the proposed model is valid and reliable for the context of developing countries, especially Indonesia. The valid and reliable model of the study is expected to address contribution as a guideline for future researchers in assessing the use of the Internet in higher education.

From the assessment of the structural model, the results of the bootstrapping analysis report that PEU has a significant influence on PU. It is in line with the report from [8] and [9] who revealed that PU was significantly predicted by PEU. Similarly, $\mathrm{PEU}$ is also reported to be the strongest predictor for AT which agrees to the previous report [10]. PEU is also reported to influence ST. Similar results from [4] who reported that PEU is significant for affecting ST. With more than 100 million internet users in Indonesia that are dominated by millennial, pre-service teachers' PEU can be a strong foundation for educational stakeholders, especially in developing countries, to improve the integration of technology in pre-service teacher training programs. The fact that PEU has a significant role in predicting PU, ST, and AT could be the reasons why the pre-service teachers are accustomed to using the Internet for a daily basis and learning; their perceived ease of use is highly in line with this fact. Therefore, the use 
of the Internet should always be developed, especially for educational institutions in rural areas where the Internet is still considered as an exclusive item.

PU in this study is reported to have a significant effect on AT. This path relationship is coherent with earlier researchers informing that AT was affected by users' PU in using the Internet [6] and Google apps [9]. The findings also verify that PU has an essential influence on IU which is similar to some previous studies' results $[6,7,9)$. This means that Indonesian pre-service teachers IU are dependent on their perceptions of the benefits of technology use in their learning. On the other hand, the results of the PLS-SEM revealed that Indonesian pre-service teachers' PU does not significantly predict ST meaning that there is no strong correlation between their perceptions of benefits and their satisfaction in using the Internet. This fact contrasts earlier findings which showed a significant correlation between the two, PU and ST $(4,10,11]$. However, it is similar to the result of [2] that reported PU had a low effect on ST. It might be triggered by the fact that the infrastructure and facilities of the Internet in Indonesian higher institutions are still lacking. Therefore, the Internet service providers, educational institution and Indonesian telecommunication providers should facilitate appropriate internet network services, to improve users' satisfaction.

AT is reported to positively predict IU. Indonesian pre-service teachers' behavior towards the Internet is a key factor predicting their intention to use it in learning which was also reported by earlier studies [6, 12]. Their high positive attitudes towards the Internet might be due to the fact that the Internet has been a very integral part of their learning for sources of knowledge, information, and entertainment. However, IU is not predicted by ST; it counters the results of some studies [13, 14] informing that ST was a key determinant for IU or actual use of technology into instruction. Regarding this, training on the use of the Internet in educational activities is suggested to always be promoted.

\section{Conclusion and Implications}

The adoption of the Internet in higher education especially in developing countries is very important in obtaining an improvement in educational sector for the 4.0 industrial revolutions. The Internet can have many benefits to change tools for teachers, students [3]. This study has reaffirmed an extended TAM framework to be a valid and reliable model in predicting factors influencing the intention to use technology, especially the Internet, in another setting and context. It has also disseminated the use of PLS-SEM to measure and assess the proposed model as well as establish the correctness of the generalizability of the extended TAM framework assessing Indonesian pre-service teachers' intention to use the Internet in learning. In addition, the current study has also confirmed that ST as the extended construct involved in the TAM framework can be beneficial for future researchers who have similar interests to conduct studies regarding the use of technology in higher education institutions. The study is also expected to support findings of previous studies, especially those which reported the findings regarding technology integration in classroom learning, especially in developing countries like Indonesia. 
Besides recommendations and suggestions offered for future studies, the current study possessed some limitations. This study was confined to pre-service teachers who studied in only five Indonesian universities while there are many other higher institutions that have implemented the Internet services in Indonesia. This study also excluded the demographic information differences regarding the TAM constructs, perceived ease of use, perceived usefulness, attitudes, intention to use, and an additional construct, satisfaction. The participants of this study should be more various such as schoolteachers, post-graduate students, lecturers, and administrative staff. In order to generalize the findings, future elaboration and investigation on crosscultural validation of the TAM with satisfaction and other external constructs should be promoted to shed more light on users' intention to use the Internet, online research, m-learning, information systems, e-portfolios, and other research objects.

\section{$7 \quad$ References}

[1] Khan, K. U. R., Zaman, R. U., \& Reddy, A. V. (2010). An Analytical Framework for the Assessment of the Mobile IP overhead involved in the Integrated Internet-MANET. International Journal of Interactive Mobile Technologies (iJIM), 4(1), 22-23. https://doi.or g/10.3991/ijim.v4i1.1027

[2] Oyelere, S. S., Suhonen, J., \& Sutinen, E. (2016). M-Learning: A new paradigm of learning ICT in Nigeria. International Journal of Interactive Mobile Technologies (iJIM), 10(1), 35-44. https://doi.org/10.3991/ijim.v10i1.4872

[3] Kuo, Y. C., Walker, A. E., Schroder, K. E., \& Belland, B. R. (2014). Interaction, Internet self-efficacy, and self-regulated learning as predictors of student satisfaction in online education courses. The internet and higher education, 20, 35-5. https://doi.org/10.1016/j.i heduc.2013.10.001

[4] Islam, A. A., Mok, M. M. C., Xiuxiu, Q., \& Leng, C. H. (2018). Factors influencing students' satisfaction in using wireless internet in higher education: Cross-validation of TSM. The Electronic Library, 36(1), 2-2. https://doi.org/10.1108/el-07-2016-0150

[5] Davis, F., Bagozzi, R.P. and Warshaw, P.R. (1989), "User acceptance of computertechnology: a comparison of two theoretical models. Management Science, 35(8), 9821003. https://doi.org/10.1287/mnsc.35.8.982

[6] Buabeng-Andoh, C., Yaokumah, W., \& Tarhini, A. (2019). Investigating students' intentions to use ICT: A comparison of theoretical models. Education and Information Technologies, 24(1), 643-66. https://doi.org/10.1007/s10639-018-9796-1

[7] Muhaimin, Habibi, A., Mukminin, A., Asrial, Pratama, R., \& Harja, H. (2019). Predicting factors affecting intention to use Web 2.0 in learning: Evidence from science education. Journal of Baltic Science in Education, 18(4), 595. https://doi.org/10.33225/jbse/19.18.595

[8] Nikou, S. A., \& Economides, A. A. (2017). Mobile-based assessment: Investigating the factors that influence behavioral intention to use. Computers \& Education, 109, 56-73. https://doi.org/10.1016/j.compedu.2017.02.005

[9] Rejón-Guardia, F., Polo-Peña, A. I., \& Maraver-Tarifa, G. (2019). The acceptance of a personal learning environment based on Google apps: The role of subjective norms and social image. Journal of Computing in Higher Education, 1-31. https://doi.org/10.1007/s 12528-019-09206-1 
[10] Lee, D. Y., \& Lehto, M. R. (2013). User acceptance of YouTube for procedural learning: An extension of the Technology Acceptance Model. Computers \& Education, 61, 193-208. https://doi.org/10.1016/j.compedu.2012.10.001

[11] Kumar, R. G., \& Ravindran, S. (2012). An empirical study on service quality perceptions and continuance intention in mobile banking context in India. Journal of Internet Banking and Commerce, 17 (1), 1-22

[12] Lai, C., Wang, Q., \& Lei, J. (2012). What factors predict undergraduate students' use of technology for learning? A case from Hong Kong. Computers \& Education, 59(2), 569579. https://doi.org/10.1016/j.compedu.2012.03.006

[13] de Melo Pereira, F. A., Ramos, A. S. M., Gouvêa, M. A., \& da Costa, M. F. (2015). Satisfaction and continuous use intention of e-learning service in Brazilian public organizations. Computers in Human Behavior, 46, 139-148. https://doi.org/10.1016/j.chb. $\frac{2015.01 .016}{\text { J. J., }}$

[14] Joo, Y. J., Park, S., \& Shin, E. K. (2017). Students' expectation, satisfaction, and continuance intention to use digital textbooks. Computers in Human Behavior, 69, 83-9. https://doi.org/10.1016/j.chb.2016.12.025

[15] Sjøberg, D. I., Hannay, J. E., Hansen, O., Kampenes, V. B., Karahasanovic, A., Liborg, N. K., \& Rekdal, A. C. (2005). A survey of controlled experiments in software engineering. IEEE transactions on software engineering, 31(9), 733-753. https://doi.org/10.1109/tse.20 $\underline{05.97}$

[16] Behr, D. (2017). Assessing the use of back translation: The shortcomings of back translation as a quality testing method. International Journal of Social Research Methodology, 20(6), 573-584. https://doi.org/10.1080/13645579.2016.1252188

[17] Hair, J. F., Risher, J. J., Sarstedt, M., \& Ringle, C. M. (2019). When to use and how to report the results of PLS-SEM. European Business Review, 31(1), 2-24. https://doi.org/10. 1108/ebr-11-2018-0203

[18] Hair, J. F., Black, W. C., Babin, B. J., \& Anderson, R. E. (2010), Multivariate data analysis: a global perception. Pearson, Upper Saddle River, NJ

[19] Habibi, A., Yusop, F. D., \& Razak, R. A. (2020). The role of TPACK in affecting preservice language teachers' ICT Integration during teaching practices: Indonesian context. Education and Information Technologies, 25(3), 1929-1949. https://doi.org/10.1007/s106 39-019-10040-2

[20] Papadakis, S. (2018). Evaluating pre-service teachers' acceptance of mobile devices with regards to their age and gender: a case study in Greece. International Journal of Mobile Learning and Organisation, 12(4), 336-352. https://doi.org/10.1504/ijmlo.2018.10013372

[21] Kalogiannakis, M., \& Papadakis, S. (2017). Pre-service kindergarten teacher's acceptance of "ScratchJr" as a tool for learning and teaching computational thinking and Science education. In Proceedings of the $12^{\text {th }}$ Conference of the European Science Education Research Association (ESERA), Research, practice and collaboration in science education (pp. 21-25).

[22] Prasojo, L., Habibi, A., Mukminin, A., Sofyan, S., Indrayana, B., \& Anwar, K. (2020). Factors Influencing Intention to Use Web 2.0 in Indonesian Vocational High Schools. International Journal of Emerging Technologies in Learning (iJET), 15(5), 100-118. https ://doi.org/10.3991/ijet.v15i05.10605

[23] Kalogiannakis, M., \& Papadakis, S. (2019). Evaluating pre-service kindergarten teachers' intention to adopt and use tablets into teaching practice for natural sciences. International Journal of Mobile Learning and Organisation, 13(1), 113-127. https://doi.org/10.1504/ijml $\underline{0.2019 .10016617}$ 
[24] Aman, A., Prasojo, L. D., Sofwan, M., Mukminin, A., Habibi, A., \& Yaqin, L. N. (2020). Factors affecting indonesian pre-service teachers' use of m-LMS: A mix method study. International Journal of Interactive Mobile Technologies (iJIM), 14(06), 137-147. https:// doi.org/10.3991/ijim.v14i06.12035

\section{Authors}

Ali Sadikin is a senior lecturer of Program Pendidikan Biologi, Universitas Jambi, 1. Lintas Sumatera Jl. Jambi - Muara Bulian, Km. 15, Mendalo Darat, Kec. Jambi Luar Kota, Kabupaten Muaro Jambi, Jambi 36122, Indonesia. He is the head of pre-service teachers' training program of Universitas Jambi. He is the editor in chief of BIODIK Journal. Email: alisadikin@unja.ac.id

Akhmad Habibi is a researcher working at Universitas Jambi, Lintas Sumatera Jl. Jambi - Muara Bulian, Km. 15, Mendalo Darat, Kec. Jambi Luar Kota, Kabupaten Muaro Jambi, Jambi 36122, Indonesia. Focusing on statistics and education, he has published his work in some journals (e.g., Education and Information Technologies, Heliyon, Data in Brief, SageOpen, The Qualitative Report, Electronic Journal of eLearning, International Journal of Emerging Technology and others). He is a reviewer for some reputable journals like Heliyon, IEEE Access, SageOpen, Accountability in Research, International Journal of Interactive Mobile Technology, e-learning and digital media, and others.

Erick Sanjaya is a lecturer of Program Pendidikan Biologi, Universitas Jambi, 1. Lintas Sumatera Jl. Jambi - Muara Bulian. Km. 15, Mendalo Darat, Kec. Jambi Luar Kota, Kabupaten Muaro Jambi, Jambi 36122, Indonesia.

Dwi Candra Setiawan is a lecturer of Dwi Candra Setiawan Program Studi Pendidikan Biologi, IKIP Budi Utomo, Malang Jl. Simpang Arjuno No.14B, Kauman, Kec. Klojen, Kota Malang, Jawa Timur 65119, Indonesia

Try Susanti is a senior lecturer of Fakultas Tarbiyah dan Keguruan, UIN Sulthan Thaha Saifuddin, rif Rahman Hakim No.111, Simpang IV Sipin, Kec. Telanaipura, Kota Jambi, Jambi 36361, Indonesia.

Ferdiaz Saudagar is a lecturer of Faculty of Education and Teacher Training, Universitas Jambi, 1. Lintas Sumatera Jl. Jambi - Muara Bulian No.Km. 15, Mendalo Darat, Kec. Jambi Luar Kota, Kabupaten Muaro Jambi, Jambi 36122, Indonesia.

Article submitted 2020-02-01. Resubmitted 2020-08-20. Final acceptance 2020-11-29. Final version published as submitted by the authors. 